\title{
One-Third of Perinatal Women Living with HIV Had Perinatal Depression in Gondar Town Health Facilities, Northwest Ethiopia
}

This article was published in the following Dove Press journal: HIVIAIDS - Research and Palliative Care

\author{
Mulualem Mihret Gelaw' \\ Ejigu Gebeye Zeleke ${ }^{2}$ \\ Mezgebu Silamsaw Asres $\mathbb{D}^{3}$ \\ Mebratu Mitiku Reta ${ }^{3}$ \\ 'Felegehiwot Referral Hospital, Bahirdar, \\ Ethiopia; ${ }^{2}$ Department of Epidemiology \\ and Biostatistics, Institution of Public \\ Health, University of Gondar, Gondar, \\ Ethiopia; ${ }^{3}$ Department of Internal \\ Medicine, School of Medicine, University \\ of Gondar, Gondar, Ethiopia
}

Background: Depression is the most common co-morbidity among perinatal women living with HIV. It affects client's adherence to care and treatment, which results in increased viral load; further exposing women to opportunistic infections that reduce quality-of-life. A cumulative effect of these may increase mother-to-child transmission of HIV.

Methods: An institution-based cross-sectional study was conducted among perinatal women living with HIV in Gondar town health facilities, Northwest Ethiopia from October 1-30, 2018. A single population proportion formula was used to calculate the sample size. The sample was stratified and proportionally allocated to each health facility. Participants were chosen from each stratum independently using a simple random sampling technique. A total of 422 study participants were selected. The World Health Organization (WHO) 20-item selfreported questionnaire (SRQ-20) was used to measure perinatal depression among women living with HIV. Perceived stigma was measured using HIV stigma scale. Women were interviewed at the PMTCT clinic during follow-up care, and clinical variables were extracted from client chart. Bi-variable and multivariable logistic regression models were used to identify factors associated with perinatal depression. Variables having an odds ratio with 95\% confidence interval and a $P$-value less than 0.05 were taken as significant variables associated with perinatal depression.

Results: The prevalence of perinatal depression among women living with HIV was found to be $38.4 \%$ (95\% CI=34.1-43.1\%). Fair and poor ART drug adherence (AOR=5.44; $95 \%$ $\mathrm{CI}=2.81-10.56 \%$ ), the presence of comorbid illness (AOR $=3.24 ; 95 \% \mathrm{CI}: 1.83-5.75$ ), being on second line ART $(\mathrm{AOR}=2.97 ; 95 \% \mathrm{CI}=1.08-8.17)$, perceived stigma (AOR=3.61; 95\% $\mathrm{CI}=2.11-6.17)$, and suicidal ideation $(\mathrm{AOR}=3.89 ; 95 \% \mathrm{CI}=1.28-11.81)$ were factors associated with perinatal depression.

Conclusion: The prevalence of perinatal depression among women living with HIV was found to be high. Adherence counseling needs to be strengthened; preventing first line treatment failure has to be encouraged; greater emphasis has to be given for those women on second line ART. Early identification and management of co-morbidity has to be considered. HIV positive perinatal women need counseling to reduce HIV-related perceived stigma.

Keywords: perinatal women, HIV/AIDS, depression, Ethiopia

\section{Introduction}

Depression is a common mental disorder characterized by depressed mood, loss of interest or pleasure, decreased energy, feeling of guilt or low self-worth, disturbed sleep or appetite, and poor concentration. ${ }^{1}$ It is estimated to be the second disease
Correspondence: Mebratu Mitiku Reta Email mebretann16@gmail.com 
burden on the globe by $2020 .^{2}$ However, it is a neglected mental health disorder among people living with HIV in sub-Saharan Africa. ${ }^{3}$ Perinatal depression is a kind of depression that occurs during the perinatal period (pregnancy up to 1 year of postpartum). ${ }^{4}$ In low and middle income countries, the prevalence of perinatal depression is estimated to be $15-25 \% .{ }^{5}$ Depression is the most common illness among pregnant women living with HIV. ${ }^{6}$ It is associated with significant adverse public health consequences. ${ }^{7}$ This might have a negative effect on their adherence to care and treatment which subsequently contribute to rapid viral multiplication and mutation that results in treatment failure. ${ }^{8}$ The high viral load due to treatment failure causes increased vertical transmission of HIV. ${ }^{9,10}$ According to reports by the WHO, UNICEF, and UNAIDS on HIV/AIDS, every year about 1.49 million infants born from women living with HIV. ${ }^{11}$ Depression during pregnancy is a public health concern because it is associated with poor fetal and delivery outcomes, risky behaviors, and poor uptake of antenatal care. ${ }^{12}$ Perinatal depression can introduce threats to maternal and child health during pregnancy and the postnatal period ${ }^{13}$ In particular in low and middle income countries where the threat of maternal morbidity and mortality is unacceptably high. Adverse consequences of maternal depression for women living with HIV and their children may include low uptake and poor adherence to interventions in preventing mother-to-child transmission of HIV. ${ }^{14}$ Maternal depression also affects child health, including risks of perinatal HIV transmission, poor physical health, impaired cognitive, behavioral, and psychomotor development and slow socio-economic development. ${ }^{15,16}$ Women from developing countries are usually exposed to risk factors to develop perinatal depression; such as poor socioeconomic status and unintended pregnancy. ${ }^{17} \mathrm{~A}$ study conducted in Ethiopia indicated that the prevalence of depression among women who do not have Ante Natal Care (ANC) follow-up was $31.5 \% .{ }^{18}$ The antenatal care clinic is place where women receive healthcare during pregnancy. ${ }^{19}$ Depression in women living with HIV might be higher than women who do not have HIV infection. Having HIV and depression together is a double burden for the pregnant women. However, there is still no sufficient data which describes its magnitude and associated factors. Therefore, the aim of this study was to assess the prevalence of perinatal depression and associated factors among women living with HIV in Gondar town health facilities, North West Ethiopia.

\section{Materials and Methods}

\section{Study Design and Setting}

An institution-based cross-sectional study was conducted in Gondar town health facilities. The university hospital and five health facilities that were providing PMTCT care were involved in the study. Those women living with HIV who visit the selected health facilities in their regular follow-up of PMTCT service were interviewed during data collection period. Women who were seriously ill and unable to communicate and transferred out were excluded from the study.

\section{Sample Size and Sampling Procedures}

The sample size was calculated using a single population proportion formula with the assumption of proportion of perinatal depression $(50 \%)$ and $5 \%$ margin of error. The final sample size was found to be 384 . By adding a $10 \%$ non-response rate the total sample size became 422 . The sample was stratified and allocated proportionally to each health facilities. Simple random sampling was used to collect data in six health facilities independently.

\section{Data Collection Tools and Procedures}

Data was collected using the Amharic version of the interviewer administered questionnaire from October 1-30, 2018. The questionnaire was first prepared in English but later it was translated into Amharic by a language expert, and then it was translated back to English by another language expert to check its consistency. Two trained psychiatric nurses participated in the data collection process. The WHO 20 items self-reporting questionnaire (SRQ-20) was used to measure perinatal depression. This tool is superior to the Edinburgh postnatal depression scale (EPDS) across all domains in evaluating perinatal depression in a low income setting. ${ }^{20}$ Perinatal depression was considered using a cut-off point of 6 and above. ${ }^{20}$ The Oslo-3 social support scale which has a score of 3-14 was used to determine social support characteristics. The Oslo-3 social support scale with a score of 3-8 was poor, 9-11 moderate, and 12-14 strong social support. ${ }^{21}$ Perceived stigma was measured using the HIV stigma scale, and participants who scored above the mean were considered to have perceived stigma. $^{22}$ Suicidal ideation was assessed using the Composite International Diagnostic Interview (CIDI). ${ }^{23}$ Suicidal ideation was recorded if the respondent responded yes to the question: have you ever seriously thought about committing suicide? And a suicidal attempt was recorded if 
the respondents said yes to the question: have you ever attempted suicide? Drug adherence was assessed using a self-reporting questionnaire. History of alcohol use was assessed by asking "have you ever used any alcohol since the beginning of your pregnancy?" The Amharic version of the semi-structured pre-tested and interviewer administered questionnaire was used to collect data on the sociodemographic characteristics of participants. Secondary data was obtained from the patient chart for clinical information (recent CD4 count, recent viral load, ART regimen, and other variables).

\section{Data Processing and Analysis}

The collected data was manually checked for its completeness before entering into EPI INFO version 7. Then data was exported to SPSS version 20 for analysis. Primarily, a binary logistic regression model was used; variables with a $P$-value $\leq 0.2$ from this model were fitted into the multivariable logistic regression model in order to avoid confounding factors. Finally, an adjusted odds ratio with $95 \%$ CI was calculated; variables with a $P$-value less than 0.05 were considered to be significant factors associated with perinatal depression.

\section{Result}

A total of 414 eligible clients were included in the study with a response rate of $98.1 \%$. The mean age of the respondents was $30.1(\mathrm{SD}= \pm 4.65)$ years. The majority of women were aged 26-33 years. About 75\% of women were married; nearly one-third $(133,32.1 \%)$ of the women had completed secondary school. The majority of the respondents $(374,90.3 \%)$ were urban dwellers (Table 1)

About three quarters of the study participants had had two-to-four pregnancies including the current one. About $99 \%$ of the participant's children were tested for HIV/ AIDS; $20.5 \%$ of them were positive for the HIV test. One hundred and twenty-six (30.44\%) participants had a history of child death, while $22.5 \%$ had a history of abortion. Around $16 \%$ of the respondents had a history of alcohol use during their current pregnancy. About $8 \%$ of the study participants had suicidal ideation in the 12 months prior to data collection (Table 2).

Close to one-third of the respondents had comorbid illness; such as hypertension, diabetes mellitus, and tuberculosis. The majority of the participants were on the first line ART regimen and $56 \%$ of them were on TDF/3TC/ EFV. About $81.6 \%$ of respondents had good ART adherence (taken $>95 \%$ of drugs prescribed). About $60 \%$ of the study participants knew that their partners were HIV positive. One fourth of the participants had partners with unknown HIV status; $15 \%$ of participants had partners with negative HIV test results. Among the study participants, $6.5 \%$ of them were reactive for the syphilis test. The majority (88.6\%) of women living with HIV disclosed their HIV status, of which about three quarters (74\%) had also disclosed it to their partner. Close to half of the respondents $(47.3 \%)$ had perceived stigma. Fifty-six $(13.5 \%)$ of the respondents had a CD4 count less than $200 \mathrm{cell} / \mathrm{mm}^{3}$ and $262(63.3 \%)$ of respondents had started ART before pregnancy. None of respondents had strong social support (Table 3 ).

This study showed that $38.4 \%$ (95\% CI 34.2-43.1\%) of perinatal women living with HIV were found to have depression. The ART drug adherence, having comorbid illness, being on second line ART, perceived stigma, and suicidal ideation were significant and independent factors associated with perinatal depression. Women with fair and poor ART drug adherence were 5-times more likely to have perinatal depression $(\mathrm{AOR}=5.44 ; 95 \% \mathrm{CI}=2.81-10.56)$. Women with comorbid illness had 3-times more odds of depression than those with no comorbidity $(\mathrm{AOR}=3.24$; $95 \% \mathrm{CI}=1.83-5.75)$ and those women on second line ART were 3-times more depressed compared to those who were on first line ART (AOR=2.97; 95\% CI=1.08-8.19). In addition, those women with perceived HIV stigma were 3.6-times more likely to have perinatal depression (AOR=3.61; 95\% CI=2.11-6.17) and those women with suicidal ideation were nearly 4-times more likely to have depression than their counterparts $(\mathrm{AOR}=3.89 ; 95 \%$ $\mathrm{CI}=1.28-11.81$ ) (Supplementary Table S1)

\section{Discussion}

The prevalence of perinatal depression among women living with HIV was found to be $38.4 \%$ (95\% CI=34.1$43.1 \%$ ). This finding is almost in-line with the study conducted in Uganda (39\%). ${ }^{24}$ This might be due to socioeconomic similarity between the two countries. However, it is higher than the findings in Cape Town, South Africa $(11 \%){ }^{25}$ This variation might be due to differences in sociodemographic characteristics and tools used to measure depression. For instance, in the study conducted in Cape Town, depression was assessed using the Edinburgh postnatal depression scale (EPDS). The finding of this study was also higher than a systematic review conducted in Ethiopia $(25.8 \%)^{26}$ and other low and middle income 
Table I Sociodemographic Characteristics of HIV Positive Perinatal Women in Gondar Town Health Institutions, Northwest Ethiopia, $2018(n=4 \mid 4)$

\begin{tabular}{|c|c|c|c|c|c|}
\hline \multirow[t]{2}{*}{ Variables } & \multirow[t]{2}{*}{ Category } & \multirow[t]{2}{*}{ Frequency } & \multicolumn{2}{|l|}{ Depression } & \multirow[t]{2}{*}{ Percent } \\
\hline & & & Yes & No & \\
\hline The outcome variable & Perinatal Women living with HIV & $4 \mid 4$ & 159 (38.4\%) & $255(61.6 \%)$ & \\
\hline \multirow[t]{6}{*}{ Age } & $|8-2|$ & 10 & 4 & 6 & 2.4 \\
\hline & $22-25$ & 56 & 26 & 30 & 13.5 \\
\hline & $26-29$ & 129 & 45 & 84 & 31.2 \\
\hline & $30-33$ & 118 & 39 & 79 & 28.5 \\
\hline & $34-37$ & 73 & 29 & 44 & 17.6 \\
\hline & $38-41$ & 28 & 16 & 12 & 6.8 \\
\hline \multirow[t]{4}{*}{ Marital status } & Married & 300 & 89 & 211 & 72.5 \\
\hline & Single & 18 & 13 & 5 & 4.3 \\
\hline & Divorced or widowed & 41 & 25 & 16 & 9.9 \\
\hline & Separated & 55 & 32 & 23 & 13.3 \\
\hline \multirow[t]{2}{*}{ Residence } & Rural & 40 & 19 & 21 & 9.7 \\
\hline & Urban & 374 & 236 & 138 & 90.3 \\
\hline \multirow[t]{5}{*}{ Level of education } & Unable to read and write & 72 & 34 & 38 & 17.4 \\
\hline & Able to read and write only & 15 & 6 & 9 & 3.6 \\
\hline & Primary school & 94 & 41 & 53 & 22.7 \\
\hline & Secondary school & 133 & 45 & 88 & 32.1 \\
\hline & Diploma and above & 100 & 30 & 70 & 24.2 \\
\hline \multirow[t]{3}{*}{ Living status } & Alone & 94 & 59 & 35 & 22.7 \\
\hline & With family & 19 & 11 & 8 & 4.6 \\
\hline & With husband & 301 & 89 & 212 & 72.7 \\
\hline \multirow[t]{5}{*}{ Occupation } & No occupation & 7 & 5 & 2 & 1.7 \\
\hline & Government employee & 92 & 29 & 68 & 23.4 \\
\hline & Housewife & 210 & 71 & 139 & 50.7 \\
\hline & Daily labor & 59 & 41 & 18 & 14.3 \\
\hline & Merchant & 41 & 13 & 28 & 9.9 \\
\hline \multirow[t]{5}{*}{ Husband occupation } & Government employed & 122 & 39 & 115 & 40.6 \\
\hline & Farmer & 32 & 14 & 18 & 10.6 \\
\hline & Daily labor & 47 & 34 & 33 & 15.6 \\
\hline & Merchant & 52 & 21 & 41 & 17.3 \\
\hline & Other* & 48 & 17 & 31 & 15.9 \\
\hline \multirow[t]{7}{*}{ Income } & $0-585$ & 64 & 38 & 26 & 15.5 \\
\hline & $586-1,650$ & 82 & 44 & 38 & 19.8 \\
\hline & $\mathrm{I}, 65 \mathrm{I}-3, \mathrm{I} 45$ & 122 & 39 & 83 & 29.5 \\
\hline & $3,146-5,195$ & 68 & 22 & 46 & 16.4 \\
\hline & $5,196-7,758$ & 48 & 11 & 37 & 11.6 \\
\hline & $7,759-10,833$ & 26 & 4 & 22 & 6.3 \\
\hline & $>10,833$ & 4 & I & 3 & 1 \\
\hline
\end{tabular}

Notes: *Driver, unemployed/no occupation.

countries $(18.9 \%){ }^{27}$ This may be due to the fact that this single study was compared with a systematic review with pooled prevalence from different studies. In addition, a systematic review conducted in Ethiopia was among perinatal women in general, and ours is specific to perinatal women living with HIV. On the other hand, this study is lower than studies done in South Africa (48.7\%) and Chicago, IL (44\%). ${ }^{28,29}$ This discrepancy might be due to 
Table 2 Behavioral and Other Characteristics Among HIV Positive Perinatal Women in Gondar Town Health Institutions, Northwest Ethiopia, $2018(n=414)$

\begin{tabular}{|c|c|c|c|c|c|}
\hline \multirow[t]{2}{*}{ Variables } & \multirow[t]{2}{*}{ Category } & \multirow[t]{2}{*}{ Frequency } & \multicolumn{2}{|l|}{ Depression } & \multirow[t]{2}{*}{ Percent } \\
\hline & & & Yes & No & \\
\hline Outcome variable & Perinatal women living with HIV & 414 & 159 (38.4\%) & $255(61.6 \%)$ & \\
\hline Alcohol use & $\begin{array}{l}\text { Yes } \\
\text { No }\end{array}$ & $\begin{array}{l}68(16.4 \%) \\
346(83.6 \%)\end{array}$ & $\begin{array}{l}22(32.4 \%) \\
137(39.6 \%)\end{array}$ & $\begin{array}{l}46(67.6 \%) \\
209(60.4 \%)\end{array}$ & $\begin{array}{l}16.4 \\
83.6\end{array}$ \\
\hline Chewing khat & $\begin{array}{l}\text { Yes } \\
\text { No }\end{array}$ & $\begin{array}{l}5(1.2 \%) \\
409 \text { (98.8\%) }\end{array}$ & $\begin{array}{l}2(20 \%) \\
157(38.4 \%)\end{array}$ & $\begin{array}{l}3(60 \%) \\
252(61.6 \%)\end{array}$ & $\begin{array}{l}1.2 \\
98.8\end{array}$ \\
\hline Thought of committing suicide & $\begin{array}{l}\text { Yes } \\
\text { No }\end{array}$ & $\begin{array}{l}34(8.2 \%) \\
360(92.8 \%)\end{array}$ & $\begin{array}{l}28(82.4 \%) \\
|3|(36.4 \%)\end{array}$ & $\begin{array}{l}6(17.6 \%) \\
249(63.6 \%)\end{array}$ & $\begin{array}{l}8.2 \\
91.8\end{array}$ \\
\hline Suicide attempt & $\begin{array}{l}\text { Yes } \\
\text { No }\end{array}$ & $\begin{array}{l}4(1 \%) \\
410(99 \%)\end{array}$ & $\begin{array}{l}3(75 \%) \\
156(38 \%)\end{array}$ & $\begin{array}{l}\text { I (25\%) } \\
254(62 \%)\end{array}$ & $\begin{array}{l}1 \\
99\end{array}$ \\
\hline Child death & $\begin{array}{l}\text { Yes } \\
\text { No }\end{array}$ & $\begin{array}{l}\text { I26 (30.4\%) } \\
288(69.6 \%)\end{array}$ & $\begin{array}{l}73(57.9 \%) \\
106(36.8 \%)\end{array}$ & $\begin{array}{l}53(42.1 \%) \\
182(63.2 \%)\end{array}$ & $\begin{array}{l}30.44 \\
69.56\end{array}$ \\
\hline Future plan to be pregnant & $\begin{array}{l}\text { Yes } \\
\text { No }\end{array}$ & $\begin{array}{l}100(24.2 \%) \\
314(75.8 \%)\end{array}$ & $\begin{array}{l}59(59 \%) \\
100(31.8 \%)\end{array}$ & $\begin{array}{l}41 \text { ( } 41 \%) \\
214(68.2 \%)\end{array}$ & $\begin{array}{l}24.15 \\
75.85\end{array}$ \\
\hline
\end{tabular}

the variation in sample size; differences in lifestyle of the study participants and tools used to assess perinatal depression. A relatively small size (244) was used in Chicago, and depression was measured by the Center for Epidemiological Studies scale (CES-DS), while EPDS was used in South Africa.

In the current study, clinical and behavioral characteristics were associated with perinatal depression. Respondents who had fair and poor adherence to their ART drug were 5-times more odds of perinatal depression than those who had good drug adherence $(\mathrm{AOR}=5.44$; 2.81-10.56). This was supported by the study done in Botswana, ${ }^{14}$ South Africa, ${ }^{28}$ and Los Angeles. ${ }^{30}$ This might be due to the fact that depressed patients experience loss of interest, reduced concentration, feelings of worthlessness, and disrupt self-management activities which may increase poor drug adherence. Patients with poor drug adherence may have repeated attacks of opportunistic infections, which might in turn lead them to develop depression. ${ }^{31}$ This shows that more emphasis has to be given in adherence counseling before treatment failure with the aim of slowing to switching to second line ART. In addition, the presence of comorbid illness was significantly associated with perinatal depression. Those women with comorbid illness had 3-times more odds of depression than those with no comorbidity ( $\mathrm{AOR}=3.24 ; 95 \%$ $\mathrm{CI}=1.83-5.75)$. This is supported by systematic electronic literature review ${ }^{32}$ and another systematic review conducted in $2007 .{ }^{33}$ The possible explanation might be due to the fact that those HIV positive women with comorbid illness are exposed to pill burden, drug side-effects, and expenses more to buy opportunistic infection (OI) treatments. In addition, due to the illness, they might have psychological, physical, and social problems (such as stress, social discrimination, unemployment) which might cause depression. ${ }^{34}$ The findings of this study revealed that being on the second line ART regimen was a significant factor associated with perinatal depression. Those women living with HIV who were on the second line ART had 3-times more odds of depression than those who were on the first line ART (AOR=2.97; 95\% CI=1.08-8.19). This is supported by a study done in Bahir Dar. ${ }^{35}$ This might be due to the fact that patients who are on second line ART needs to take more than two pills per day, and second line drugs have more frequent and severe side-effects, which makes the women depressed. ${ }^{36}$ In addition, patients on second line therapy may worry about their future if they failto be treated by second line ART drugs. ${ }^{37}$

In another study, perceived stigma was another significant factor associated with depression. Those women living with HIV having perceived stigma were 3.6-times more likely to have perinatal depression $(\mathrm{AOR}=3.61$; $95 \% \mathrm{CI}=2.11-6.17)$. This is in line with the findings of the studies conducted in Addis Ababa, ${ }^{38,39}$, Tigray, ${ }^{40}$ and 
Table 3 Clinical Characteristics Among HIV Positive Perinatal Women in Gondar Town Health Institutions, Northwest Ethiopia, 2018 $(n=4 \mid 4)$

\begin{tabular}{|c|c|c|c|c|c|}
\hline \multirow[t]{2}{*}{ Variables } & \multirow[t]{2}{*}{ Category } & \multirow[t]{2}{*}{ Frequency } & \multicolumn{2}{|c|}{ Depression } & \multirow[t]{2}{*}{ Percentage } \\
\hline & & & Yes & No & \\
\hline \multirow[t]{2}{*}{ History of mental illness } & Yes & 5 & 4 & 1 & 1.2 \\
\hline & No & 409 & 155 & 254 & 98.8 \\
\hline \multirow[t]{2}{*}{ Family History of mental illness } & Yes & 5 & 3 & 2 & 1.2 \\
\hline & No & 409 & 156 & 253 & 98.8 \\
\hline \multirow[t]{2}{*}{ CD4 } & $<200$ & 56 & 27 & 29 & 13.5 \\
\hline & $\geq 200$ & 358 & 132 & 226 & 86.5 \\
\hline \multirow[t]{3}{*}{ Viral load } & Not detected & 213 & 62 & $15 \mid$ & 51.4 \\
\hline & $<1,000$ copies $/ \mathrm{mL}$ & 195 & 95 & 100 & 47.11 .4 \\
\hline & $>1,000$ copies $/ \mathrm{mL}$ & 6 & 2 & 4 & 1.4 \\
\hline \multirow[t]{2}{*}{ Syphilis test result } & Reactive & 27 & 17 & 10 & 6.5 \\
\hline & Non-reactive & 387 & 142 & 245 & 93.5 \\
\hline \multirow[t]{2}{*}{ Hemoglobin level } & $<12 \mathrm{mg} / \mathrm{dL}$ & 169 & 74 & 104 & 40.8 \\
\hline & $>12 \mathrm{gm} / \mathrm{dL}$ & 245 & 85 & $|5|$ & 59.2 \\
\hline \multirow[t]{2}{*}{ Adherence } & Good & 341 & 106 & 235 & 82.4 \\
\hline & Fair \& poor & 73 & 53 & 20 & 17.6 \\
\hline \multirow[t]{2}{*}{ Mid-upper arm circumference (MUAC) } & $<21 \mathrm{~cm}$ & 330 & 125 & 205 & 79.7 \\
\hline & $>21 \mathrm{~cm}$ & 84 & 34 & 50 & 20.3 \\
\hline \multirow[t]{2}{*}{ Regimen of ART } & Ist line & 383 & 138 & 245 & 92.5 \\
\hline & 2nd line & 31 & 21 & 10 & 7.5 \\
\hline \multirow[t]{2}{*}{ WHO stage } & Stage I & 382 & 143 & 239 & 92.3 \\
\hline & Stage II & 32 & 16 & 16 & 7.7 \\
\hline \multirow[t]{2}{*}{ Co-morbid illness* } & Yes & 130 & 81 & 49 & 31.4 \\
\hline & No & 284 & 78 & 206 & 68.6 \\
\hline \multirow[t]{3}{*}{ Partner HIV status } & Positive & 246 & 63 & 183 & 59.4 \\
\hline & Negative & 63 & 27 & 36 & 15.2 \\
\hline & Unknown & 105 & 69 & 36 & 25.4 \\
\hline \multirow[t]{4}{*}{ Timing of ART initiation } & Before pregnancy & 262 & 90 & 172 & 63.3 \\
\hline & During pregnancy & 144 & 68 & 76 & 34.8 \\
\hline & Labor \& delivery & 1 & 0 & 1 & 0.2 \\
\hline & Post-partum & 7 & 1 & 6 & 1.7 \\
\hline \multirow[t]{2}{*}{ Disclosure status } & Yes & 367 & 121 & 346 & 88.6 \\
\hline & No & 47 & 9 & 38 & 11.4 \\
\hline \multirow[t]{2}{*}{ Perceived Stigma } & Yes & 255 & 159 & 96 & 47.3 \\
\hline & No & 159 & 37 & 122 & 52.7 \\
\hline \multirow[t]{2}{*}{ Social support } & Poor & 313 & 123 & 190 & 75.6 \\
\hline & Moderate & 101 & 36 & 65 & 24.4 \\
\hline
\end{tabular}

Notes: *Diabetes, Hypertension, Tuberculosis.

Nkangala, South Africa. ${ }^{41}$ APossible reasons might be due to the fact that those HIV positive women who had perceived stigma may not have healthy socia interactions with the community; they may feel isolated from the society where they live; they may not share their feeling with friends and families; and they may try to keep 
their feelings secret. A combination of these may lead to feelings of loneliness and helplessness that finally increase the risk of depression. ${ }^{42}$

The finding of this study also showed that suicidal ideation was another factor associated with perinatal depression. Those women having suicidal ideation were at nearly 4-times more odds of depression than their counterparts $(\mathrm{AOR}=3.89 ; 95 \% \mathrm{CI}=1.28-11.81)$. This is supported by the findings of a study conducted in Cape Town and Nepal. ${ }^{25,43}$

This might be due to the fact that women with depression are more prone to have suicidal ideation, ${ }^{44}$ low coping mechanisms, and emotional stability. The struggle in choosing either self-killing or living might contribute to frequent psychological stress that finally leads to depression, and the reverse might be true. ${ }^{45,46}$

\section{Conclusion}

The findings of this study indicated that the prevalence of perinatal depression among women living with HIV was found to be high. ART drug adherence, having a comorbid illness, being on second line ART, perceived stigma, and suicidal ideation were significant and independent factors associated with perinatal depression in women living with HIV. Strengthening adherence counseling has to be emphasized, especially for those women on second line ART. Preventing first line ART treatment failure has to be encouraged. Early identification and management of comorbid illness needs special consideration. HIV positive perinatal women have to be counseled to reduce HIVrelated perceived stigma. Further study needs to be considered using a large sample size and solid study design.

\section{Strength of the Study}

We tried to address multiple variables that were hypothesized to be associated with perinatal depression.

\section{Limitation of the Study}

Some variables that may have significant associations were not included (such as having previous obstetric complications and partner violence). We used a cross-sectional study design which does not allow us to conclude the cause and effect relationship. The other limitation we assume is, it would have been good if we used wealth index in assessing participants' income. The absence of a separate analysis of depression in antenatal and postnatal women was another limitation.

\section{Abbreviations}

AIDS, acquired immune deficiency syndrome; ANC, antenatal care; ART, anti-retroviral therapy; CES-DS, center for epidemiological studies depression scale; EPDS, Edinburgh postnatal depression scale; HIV, human immune deficiency virus; MUAC, mid upper arm circumference; OI, opportunistic infection; PD, perinatal depression; PMTCT, prevention of mother-to-child transmission; SRQ-20, self-reporting questionnaire-20; UNAIDS, United Nations Program on HIV and AIDS; UNICEF, United Nations International Children's Emergency Fund; WHO, World Health Organization.

\section{Data Sharing Statement}

The datasets used and/or analyzed in this study are available from the corresponding author on reasonable request.

\section{Ethical Approval and Consent}

The ethical clearance was obtained from the College of Medicine and Health Sciences, University of Gondar. Verbal informed consent was approved by the College of Medicine and Health Science, University of Gondar, and the study was conducted in accordance with the Declaration of Helsinki. Informed verbal consent was obtained from the study participants before the beginning of the interview. The confidentiality of patient-related data was maintained by avoiding possible identifiers such as; name of the patient and medical record number. Participants identified with depressive symptoms during the data collection and those who had recent suicidal ideations were linked to the University of Gondar hospital psychiatric clinic for better evaluation and management.

\section{Consent for Publication}

Not applicable.

\section{Acknowledgment}

We acknowledge the data collectors, PMTCT care provider, and study participants.

\section{Author Contributions}

All authors made substantial contributions to the conception and design, acquisition of data, or analysis and interpretation of data; took part in drafting the article or revising it critically for important intellectual content; agreed on the journal to which the article will be submitted; gave final approval of the 
version to be published; and agreed to be accountable for all aspects of the work.

\section{Funding}

This study did not receive any specific grant from any funding agency in the public, commercial or nonprofit organizations. Nevertheless, Amhara Regional Health Office and University of Gondar as a grant of staff provided financial backing. The funder has no role on publication process.

\section{Disclosure}

The authors declare that they have no competing interests.

\section{References}

1. Marcus M, Yasamy MT, van Ommeren M, Chisholm D, Saxena S. Depression: a global public health concern. 2012.

2. Reddy M. Depression: the disorder and the burden. Indian J Psychol Med. 2010;32(1):1. doi:10.4103/0253-7176.70510

3. Hailemariam S, Tessema F, Asefa M, Tadesse H, Tenkolu G. The prevalence of depression and associated factors in Ethiopia: findings from the National Health Survey. Int J Ment Health Syst. 2012;6 (1):23. doi:10.1186/1752-4458-6-23

4. Williams J, Ryan D, Thomas-Peter K, et al. Best Practice Guidelines for Mental Health Disorders in the Perinatal Period. BC Reproductive Mental Health Program \& Perinatal Services BC; 2014.

5. Gebremichael G, Yihune M, Ajema D, Haftu D, Gedamu G. Perinatal depression and associated factors among mothers in Southern Ethiopia: evidence from Arba Minch Zuria health and demographic surveillance site. 2018:12. doi: 10.1155/2018/7930684.

6. World Health Organization. Global HIV/AIDS Response: Epidemic Update and Health Sector Progress Towards Universal Access: Progress Report 2011. Geneva: World Health Organization; 2011.

7. Senturk V, Hanlon C, Medhin G, et al. Impact of perinatal somatic and common mental disorder symptoms on functioning in Ethiopian women: the P-MaMiE population-based cohort study. $J$ Affect Disord. 2012;136(3):340-349. doi:10.1016/j.jad.2011.11.028

8. Nachega JB, Marconi VC, van Zyl GU, et al. HIV treatment adherence, drug resistance, virologic failure: evolving concepts. Infect Disord Drug Targets. 2011;11(2):167-174. doi:10.2174/1871526 11795589663

9. Stein A, Pearson RM, Goodman SH, et al. Effects of perinatal mental disorders on the fetus and child. Lancet. 2014;384(9956):1800-1819. doi:10.1016/S0140-6736(14)61277-0

10. Rahman A, Bunn J, Lovel H, Creed F. Association between antenatal depression and low birthweight in a developing country. Acta Psychiatr Scand. 2007;115(6):481-486. doi:10.1111/j.1600-0447. 2006.00950.x

11. Stringer EM, Meltzer-Brody S, Kasaro M, et al. Depression, pregnancy, and HIV: the case to strengthen mental health services for pregnant and post-partum women in sub-Saharan Africa. Lancet Psychiatry. 2014;1(2):159-162. doi:10.1016/S2215-0366(14)70273-1

12. Wachs TD, Black MM, Engle PL. Maternal depression: a global threat to children's health, development, and behavior and to human rights. Child Dev Perspect. 2009;3(1):51-59. doi:10.1111/j.17508606.2008.00077.x

13. Lancaster CA, Gold KJ, Flynn HA, Yoo H, Marcus SM, Davis MM. Risk factors for depressive symptoms during pregnancy: a systematic review. Am J Obstet Gynecol. 2010;202(1):5-14. doi:10.1016/j. ajog.2009.09.007
14. Do NT, Phiri K, Bussmann H, Gaolathe T, Marlink RG, Wester CW. Psychosocial factors affecting medication adherence among HIV-1 infected adults receiving combination antiretroviral therapy (cART) in Botswana. AIDS Res Hum Retroviruses. 2010;26(6):685-691. doi:10.1089/aid.2009.0222

15. Kingston D, Tough S, Whitfield H. Prenatal and postpartum maternal psychological distress and infant development: a systematic review. Child Psychiatry Hum Dev. 2012;43(5):683-714. doi:10.1007/ s10578-012-0291-4

16. Batten LA, Hernandez M, Pilowsky DJ, et al. Children of treatmentseeking depressed mothers: a comparison with the Sequenced Treatment Alternatives to Relieve Depression (STAR* D) child study. J Am Acad Child Adolesc Psychiatry. 2012;51(11):1185-1196. doi:10.1016/j.jaac.2012.08.020

17. Prince M, Patel V, Saxena S, et al. No health without mental health. Lancet. 2007;370(9590):859-877. doi:10.1016/S0140-6736(07) 61238-0

18. Tefera TB, Erena AN, Kuti KA, Hussen MA. Perinatal depression and associated factors among reproductive aged group women at Goba and Robe Town of Bale Zone, Oromia Region, South East Ethiopia. Maternal Health Neonatol Perinatol. 2015;1(1):12. doi:10.1186/s40748-015-0013-6

19. Australia Gos. Antenatal care during your pregnancy The Royal Australian and New Zealand college of obstetricians and gynaecologists: pregnancy birth and baby. 2020 .

20. Hanlon C, Medhin G, Alem A, et al. Detecting perinatal common mental disorders in Ethiopia: validation of the self-reporting questionnaire and Edinburgh Postnatal Depression Scale. J Affect Disord. 2008;108(3):251-262. doi:10.1016/j.jad.2007.10.023

21. Abiola T, Udofia O, Muhammed Z. Psychometric properties of the 3-item Oslo Social Support Scale among clinical students of Bayero University Kano, Nigeria. Malaysian J Psychiatry. 2013;22.

22. Reinius M, Wettergren L, Wiklander M, Svedhem V, Ekström AM, Eriksson LE. Development of a 12-item short version of the HIV stigma scale. Health Qual Life Outcomes. 2017;15(1):115. doi:10.1186/s12955-017-0691-z.

23. Bereket D, Ayano. G. Suicidal ideation and attempts among people with severe mental disorder, Addis Ababa, Ethiopia, comparative cross-sectional study. Europe PMC. 2018;17(23).

24. Kaida A, Matthews LT, Ashaba S, et al. Depression during pregnancy and the postpartum among HIV-infected women on antiretroviral therapy in Uganda. J Acq Immun Deficien Syndr. 2014;67(Suppl 4): S179. doi:10.1097/QAI.0000000000000370

25. Wong M, Myer L, Zerbe A, et al. Depression, alcohol use, and stigma in younger versus older HIV-infected pregnant women initiating antiretroviral therapy in Cape Town, South Africa. Arch Women's Ment Health. 2017;20(1):149-159. doi:10.1007/s00737-016-0688-3

26. Mersha AG, Abebe SA, Sori LM, Abegaz TM. Prevalence and associated factors of perinatal depression in Ethiopia: a systematic review and meta-analysis. Depress Res Treat. 2018;2018:1813834. doi: $10.1155 / 2018 / 1813834$

27. Fisher J, Mello M, Patel V, et al. Prevalence and determinants of common perinatal mental disorders in women in low-and lower-middle-income countries: a systematic review. Bull World Health Organ. 2012;90:139-149. doi:10.2471/BLT.11.091850

28. Peltzer K, Rodriguez VJ, Jones D. Prevalence of prenatal depression and associated factors among HIV-positive women in primary care in Mpumalanga province, South Africa. SAHARA J. 2016;13(1):60-67. doi:10.1080/17290376.2016.1189847

29. Rubin LH, Cook JA, Grey DD, et al. Perinatal depressive symptoms in HIV-infected versus HIV-uninfected women: a prospective study from preconception to postpartum. J Women's Health. 2011;20 (9):1287-1295. doi:10.1089/jwh.2010.2485

30. Kapetanovic S, Christensen S, Karim R, et al. Correlates of perinatal depression in HIV-infected women. AIDS Patient Care STDS. 2009;23(2):101-108. doi:10.1089/apc.2008.0125 
31. Moraes RP, Casseb J. Depression and adherence to antiretroviral treatment in HIV-positive men in São Paulo, the largest city in South America: social and psychological implications. Clinics (Sao Paulo, Brazil). 2017;72(12):743-749. doi:10.6061/clinics/2017(12)05

32. Arseniou S, Arvaniti A, Samakouri M. HIV infection and depression. Psychiatry Clin Neurosci. 2014;68(2):96-109. doi:10.1111/pcn.12097

33. Alder J, Fink N, Bitzer J, Hösli I, Holzgreve W. Depression and anxiety during pregnancy: a risk factor for obstetric, fetal and neonatal outcome? A critical review of the literature. J Maternal Fetal Neonat Med. 2007;20(3):189-209. doi:10.1080/14767050701209560

34. Havlik RJ, Brennan M, Karpiak SE. Comorbidities and depression in older adults with HIV. Sex Health. 2011;8(4):551-559. doi:10.1071/ $\mathrm{SH} 11017$

35. Tareke M, Addisu F, Abate A. Depression among patients attending antiretroviral treatment program in public health facilities in Bahir Dar City, Ethiopia. J Affect Disord. 2018;232:370-374. doi:10.1016/j. jad.2018.02.078

36. Beyene Gebrezgiabher B, Huluf Abraha T, Hailu E, et al. Depression among adult HIV/AIDS patients attending ART clinics at Aksum Town, Aksum, Ethiopia: a cross-sectional study. Depress Res Treat. 2019;2019:3250431. doi:10.1155/2019/3250431

37. Chen WT. Side effects of antiretroviral therapy (ART) are associated with depression in Chinese individuals with HIV: a mixed methods study. J Midwifery Women's Ealth. 2013;58(5):585. doi:10.1111/jmwh.12121

38. Desalegn Z, Wassie L, Beyene HB, Mihret A, Ebstie YA. Hepatitis $\mathrm{B}$ and human immunodeficiency virus co-infection among pregnant women in resource-limited high endemic setting, Addis Ababa, Ethiopia: implications for prevention and control measures. Eur $J$ Med Res. 2016;21. doi:10.1186/s40001-016-0211-3.

39. Tesfaw G, Ayano G, Awoke T, et al. Prevalence and correlates of depression and anxiety among patients with HIV on-follow up at Alert Hospital, Addis Ababa, Ethiopia. BMC Psychiatry. 2016;16 (1):368. doi:10.1186/s12888-016-1037-9
40. Berhe H, Bayray A. Prevalence of depression and associated factors among people living with HIV/AIDS in Tigray, North Ethiopia: a cross sectional hospital based study. Int J Pharma Sci Res. 2013;4 (2):765.

41. Peltzer K, Shikwane M. Prevalence of postnatal depression and associated factors among HIV-positive women in primary care in Nkangala district, South Africa. South Afr J HIV Med. 2011;12 (4):24-28. doi:10.4102/sajhivmed.v12i4.168

42. Barger SD, Messerli-Bürgy N, Barth J. Social relationship correlates of major depressive disorder and depressive symptoms in Switzerland: nationally representative cross-sectional study. $B M C$ Public Health. 2014;14(1):1471-2458. doi:10.1186/1471-2458-14273

43. Amiya RM, Poudel KC, Poudel-Tandukar K, Pandey BD, Jimba M, Zhang H. Perceived family support, depression, and suicidal ideation among people living with HIV/AIDS: a cross-sectional study in the Kathmandu Valley, Nepal. PLoS One. 2014;9(3):e90959. doi:10.1371/journal.pone.0090959

44. Gotlib IH, Hammen CL. Handbook of Depression. New York: Guilford Press; 2015.

45. Kalichman SC, Heckman T, Kochman A, Sikkema K, Bergholte J. Depression and thoughts of suicide among middle-aged and older persons living with HIV-AIDS. Psychiatr Services. 2000;51 (7):903-907. doi:10.1176/appi.ps.51.7.903

46. Brunstein Klomek A, Barzilay S, Apter A, et al. Bi-directional longitudinal associations between different types of bullying victimization, suicide ideation/attempts, and depression among a large sample of European adolescents. J Child Psychol Psychiatry. 2019;60 (2):209-215. doi:10.1111/jcpp.12951
HIV/AIDS - Research and Palliative Care

\section{Publish your work in this journal}

HIV/AIDS - Research and Palliative Care is an international, peerreviewed open-access journal focusing on advances in research in HIV, its clinical progression and management options including antiviral treatment, palliative care and public healthcare policies to

\section{Dovepress}

control viral spread. The manuscript management system is completely online and includes a very quick and fair peer-review system, which is all easy to use. Visit http://www.dovepress.com/testimonials.php to read real quotes from published authors. 